\title{
Thinking Outside the Box: Treating Acute Heart Failure Outside the Hospital to Improve Care and Reduce Admissions
}

\author{
ADAM D. DEVORE, MD, ${ }^{1,2}$ LARRY A. ALLEN, MD, MHS, ${ }^{3,4}$ AND ZUBIN J. EAPEN, MD, MHS ${ }^{1,2}$ \\ Durham, North Carolina; Aurora and Denver, Colorado
}

\begin{abstract}
The management of acute heart failure is shifting toward treatment approaches outside of a traditional hospital setting. Many heart failure providers are now treating patients in less familiar health care settings, such as acute care clinics, emergency departments, and skilled nursing facilities. In this review we describe the current pressures driving change in the delivery of acute heart failure and summarize the evidence regarding treatments for acute heart failure outside of the inpatient setting. We also provide considerations for the design of future treatment strategies to be implemented in alternative care settings. ( Cardiac Fail 2015;21:667-673)
\end{abstract}

Key Words: Acute heart failure, outcomes.

Current financial pressures, coupled with an urgent need to improve post-discharge outcomes, have provided incentives to change health care delivery models for patients with acute heart failure (HF). As a result, care for patients with acute HF is now being delivered in settings not typically considered to be within the purview of HF providers, such as acute care clinics, emergency departments (EDs), and skilled nursing facilities (Fig. 1). This review aims to further describe current pressures driving change in the delivery of acute $\mathrm{HF}$, summarize the evidence regarding

\footnotetext{
From the ${ }^{1}$ Duke Clinical Research Institute, Durham, North Carolina; ${ }^{2}$ Department of Medicine, Duke University School of Medicine, Durham, North Carolina; ${ }^{3}$ Division of Cardiology, University of Colorado School of Medicine, Aurora, Colorado and ${ }^{4}$ Colorado Cardiovascular Outcomes Research Consortium, Denver, Colorado.

Manuscript received April 30, 2015; revised manuscript received May 12, 2015; revised manuscript accepted May 15, 2015.

Reprint requests: Adam D. DeVore, MD, Duke Clinical Research Institute, PO Box 17969, Durham, NC 27715, USA. Tel: +1 919-684-8111; Fax: +1 919-681-9842. E-mail: adam.devore@duke.edu

Funding: Supported internally by the Duke Clinical Research Institute, Durham, North Carolina. Dr Allen is supported by the National Heart, Lung, and Blood Institute of the National Institutes of Health under award no. K23HL105896. The content is solely the responsibility of the authors and does not necessarily represent the official views of the National Institutes of Health.

See page 672 for disclosure information.

1071-9164/\$ - see front matter

(C) 2015 Elsevier Inc. All rights reserved.

http://dx.doi.org/10.1016/j.cardfail.2015.05.009
}

treatments for acute HF outside of the inpatient setting, and provide considerations when designing treatment strategies to be implemented in alternative care settings.

\section{Current Forces Driving Change in Heart Failure Care}

\section{Reducing Length of Stay While Improving Transitional Care}

Event-based reimbursement in the United States over the past few decades has provided incentives for progressively shorter lengths of stay for patients with HF. ${ }^{1}$ For Medicare beneficiaries with inpatient stays, hospitals receive payments by means of the Inpatient Prospective Payment System (IPPS). Based on a diagnosis-related group (DRG), the IPPS payment covers the inpatient stay as well as any outpatient diagnostic and admission-related outpatient nondiagnostic services provided by the institution on the date of the patient's admission or within 3 days immediately preceding the date of admission. ${ }^{2}$ Although there are other payment mechanisms designed to complement the IPPS (eg, the Hospital Value-Based Purchasing Program), the IPPS is the dominant financial motivation regarding length of stay.

This heavy focus on shorter lengths of stay may have had unintended consequences, including greater rates of premature hospital discharge and increased readmissions. ${ }^{3}$ An analysis of data from the multinational Acute Study of 

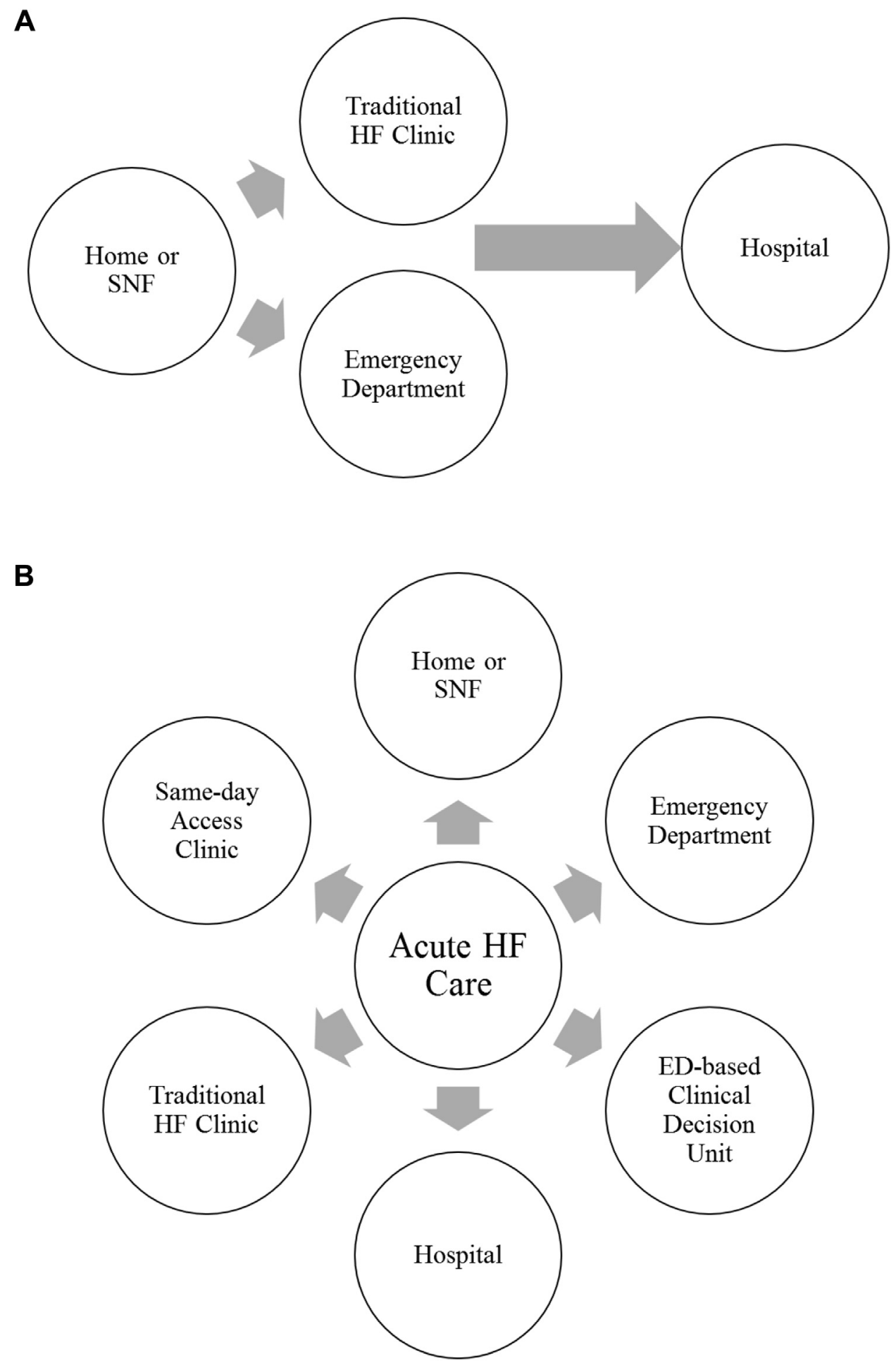

Fig. 1. New settings for acute heart failure care. This figure displays the changing settings for acute heart failure (HF) care over time. (A) The traditional model where patients would develop symptoms at home and then present to an HF clinic or emergency department (ED) for evaluation and/or initial management aimed at improving congestion and hemodynamics. Patients would then be admitted to the hospital for continued management and transitional care planning. (B) The model currently being adopted in many medical centers. Heart failure specialists can evaluate, manage, and treat patients with acute HF across multiple care settings. SNF, skilled nursing facility.

Nesiritide in Decompensated Heart Failure (ASCEND-HF) trial supports this observation. The mean length of stay by country ranged from 4.9 to 14.6 days (6.1 days in the United States), and countries with longer lengths of stay for a HF hospitalization had lower rates of 30-day allcause readmission. ${ }^{4}$ Although these data suggest that there may be a tradeoff regarding index hospitalization length of stay and readmission rates for patients with HF, to date 
there are no data to suggest that trends for shorter hospital lengths of stay have reversed course.

At the same time, in an effort to reduce health care expenditures, there is a growing focus on reducing unplanned hospital readmissions, ${ }^{5}$ including for patients with HF. Over the past 5 years, the Centers for Medicare and Medicaid Services (CMS) adopted a number of policy changes to provide additional incentives for hospitals to improve transitional care and reduce hospital readmissions. In July 2009, CMS began publicly reporting risk-standardized readmission rates for select conditions, including HF, and in October 2012 CMS extended this policy by imposing cuts in total Medicare reimbursements for higher-thanpredicted readmission rates. A recent analysis of hospitals with $\geq 25$ discharges for each condition affected by the 2012 reimbursement policy found that $73 \%$ of hospitals received a financial penalty in fiscal year $2014 .{ }^{6}$ The investigators also found that excess HF readmissions were a major driver of the penalty severity compared with the other conditions affected by the policy or structural hospital characteristics, such as number of beds or teaching hospital status. The impact of these CMS policy decisions on patient care remains unclear, but they have certainly motivated the medical community to focus on HF readmissions and related transitions in care. For example, hospitals are joining national quality improvement campaigns, such as Hospital to Home and Target: HF, to share best practices. ${ }^{7,8}$

\section{Questions Facing Heart Failure Providers}

These 2 goals, reducing length of stay while improving transitional care, have afforded opportunities for patients and HF providers to reconsider how care is delivered. This includes reconsidering the setting for each phase of management of acute HF care, from symptom onset at home (or a skilled nursing facility) to ambulatory clinic management to emergency services to transitional care (Fig. 1).

- For example, emergency medicine providers serve as decision makers for the majority of hospitalizations for acute HF and provide the bulk of care in the ED setting. ${ }^{9,10}$ How can therapeutic and disposition decisions in the early phases of acute HF improve inhospital acute HF care?

- Can collaborative decision-making with HF providers identify low-risk patients that can be discharged from the ED with early follow-up to venues such as sameday-access clinics?

- Can in-hospital resources be safely reduced by providing acute HF care in clinical decision units in the ED or same-day-access clinic with discharge directly to home?

- Can readmissions be avoided by incorporating postdischarge HF care into a same-day-access clinic?

- Is greater use of home health care and skilled nursing facilities, particularly with HF algorithms, of value?
There is growing enthusiasm for many of these concepts, but the history of HF is full of promising therapies that did not survive rigorous clinical evaluation. ${ }^{11-14}$ This history should serve as an important reminder that high-quality evidence should be used to guide changes in treatment strategies for patients with acute HF.

\section{The Evidence Base for Heart Failure Treatment Outside the Hospital}

\section{The Treatment of Acute Heart Failure in the Emergency Department}

Most initial care for acute $\mathrm{HF}$ is provided in an $\mathrm{ED},{ }^{10}$ and the ED is the portal of entry for unplanned hospital admissions for most medical conditions in the United States. The proportion of patients admitted through the ED continues to rise, generally as well as for patients with $\mathrm{HF}^{15}$ In addition, only $20 \%$ of patients with acute HF presenting to the ED are discharged home, and this proportion has been unchanged over the past 5 years. ${ }^{16}$ Although there have been many attempts to improve this process, ${ }^{17,18}$ the lack of prospectively validated risk-prediction tools to determine low versus high risk limits the ability to alter this practice. An opportunity remains for collaboration among patients, ED providers, and HF providers to develop strategies to reduce hospital resources for acute HF care.

\section{Clinical Decision Units}

The use of observation billing status for Medicare patients has steadily increased over the past decade, though this designation covers care received in both the ED and a hospital setting. ${ }^{19,20}$ In this context though, the presence of clinical decision or observation units in EDs increased from $19 \%$ in 2003 to $36 \%$ in $2007 .^{21}$

Initial studies of patients receiving care for acute HF in ED clinical decision units have been small, nonrandomized, and focused on short-term outcomes and financial viability. ${ }^{22,23}$ A retrospective study at Emory University Hospital and Emory University Hospital Midtown assessed 327 patients who received acute HF care using an accelerated treatment protocol that included cardiac monitoring, serial laboratory tests, clinical reevaluations, scheduled diuretics, and nitrates. ${ }^{22}$ Of these, 239 (73\%) were discharged directly home. There was no difference in 90-day readmission rates compared with patients admitted to the hospital after a stay in the ED clinical decision unit. These data demonstrate the feasibility of treatment protocols for acute $\mathrm{HF}$, and suggest that this care may be possible with less overall hospital resources and no increased risk of readmission. However, there is no prospective, multicenter, randomized trial evidence to support this. Additionally, little is known about the patient perspective, such as impact on quality of life, or the long-term trajectory of these patients. A hospitalization for HF is an opportunity for disease management education and initiation or titration of diseasemodifying pharmacologic therapy, benefits that may be 
difficult to achieve in an in ED clinical decision unit yet impossible to document in a small retrospective study.

\section{Post-discharge Emergency Department Care}

The ED also remains an important source of care for patients with a previous exacerbation of HF being evaluated for rehospitalization. In an analysis of ED and inpatient data available through the Healthcare Cost and Utilization Project, investigators found that among 113,033 unique patients presenting to the ED for acute HF in Florida and California, 34,793 (31\%) had >2 visits for acute HF during a 1-year period. ${ }^{24}$ In those 2 states, patients with $>2$ visits accounted for $55 \%$ of all ED visits for acute HF during the same 1-year period. These data underscore the central role of the ED in acute HF care and suggest that programs designed to optimize care for these patients in the ED could reduce rehospitalizations. However, such programs would need to be carefully designed. Rehospitalizations are associated with higher rates of subsequent adverse outcomes, such that disposition from the ED may have a lesser role for patients being considered for hospital readmission than for patients presenting to the hospital for the first time after a period of relative stability. This is somewhat at odds with public reporting and payment reforms that tend to provide greater incentive to avoid readmission than admission.

\section{Same-Day-Access Clinics}

An emerging concept is the use of a multidisciplinary HF clinic with same-day access for patients with $\mathrm{HF}^{25}$ These clinics serve as the foundational unit for HF transitional care and HF disease management programs, and they can be staffed by a variety of health care providers, eg, advanced practice providers, physicians, and social workers. Our experience suggests that many hospitals are specifically adopting the practice of same-day-access clinics for patients with HF, although there are limited data in the peer-reviewed literature to support this. Patients may benefit from intensive care in a same-day-access clinic before or after a hospitalization. Same-day-access clinics can provide treatment for worsening HF symptoms instead of a hospitalization or continue management through early follow-up after a recent hospitalization for HF, a process associated with lower hospital-level rates of early readmission. ${ }^{26}$

Duke University Hospital initiated a same-day access clinic in 2012 after observing that $>50 \%$ of HF patients admitted from the ED were 1) relatively low-risk patients who may have primarily required decongestion and 2) admitted during regular clinic hours. The Duke Heart Failure Same-Day-Access Clinic features nurse practitioners with disease management expertise and daily outpatient access to intensive therapeutic services including intravenous diuretic infusions, management and titration of evidencebased therapies, and electrolyte repletion. In the first 3 years of operation, the Duke Heart Failure Same-
Day-Access Clinic handled $>3,000$ patient visits, and the hospital concurrently saw a $10.2 \%$ reduction in the 30 day readmission rate for patients, resulting in avoidance of financial penalties for excess readmissions. This model of health care delivery requires additional study, but this example is promising.

\section{Home Health}

Another mechanism to extend HF care out of the hospital is through the use of home health services. Home health care is often integrated into transitional care programs. But as earlier reports have highlighted, the components of home health interventions for patients with HF differ, with a variable number of visits provided by individuals with dissimilar training. ${ }^{27} \mathrm{~A}$ systematic review of transitional care interventions for patients with HF concluded that home-visiting programs reduced all-cause readmissions. $^{28}$ Importantly, this benefit was seen in highintensity interventions, characterized by frequent home visits starting within 24 hours of hospital discharge. This high intensity of resources may be beneficial and feasible for some patient populations and health care systems, but not all. Additionally, there is likely an opportunity for enhanced coordination with HF providers and disease management clinics.

\section{Skilled Nursing Facilities}

Owing to many of the forces detailed above, discharges to skilled nursing facilities have increased steadily over the past few decades. ${ }^{1}$ For Medicare patients hospitalized with HF, discharges to a skilled nursing facility or intermediate care facility rose from $13.2 \%$ in 1993 to $19.6 \%$ in 2006. In an analysis of data from the Get With the Guidelines-Heart Failure (GWTG-HF) registry linked to Medicare claims, patients with HF discharged to a skilled nursing facility had an increased risk of death (hazard ratio [HR]1.76, 95\% confidence interval [CI] 1.66-1.87) and rehospitalization (HR 1.08, 95\% CI 1.03-1.14) after adjustment for key patient characteristics. ${ }^{29}$ These data highlight that there is a growing need for specialized HF care in skilled nursing facilities and that there may be opportunities for improvement in HF care. ${ }^{30}$ There are also practical considerations that patients in a skilled nursing facility are often more stable than in the hospital and have ample opportunities for disease management education and medication titration and initiation.

One strategy for improving care in skilled nursing facilities is the implementation of specialized disease management programs tailored to this setting. Studies of skilled nursing facilities have shown that HF care is limited in many skilled nursing facilities. Of 4 facilities with a high prevalence of patients with HF surveyed by Boxer et al, none had a mechanism for tracking these patients or providing HF-specific care, such as a patient-directed flexible diuretic program. ${ }^{31}$ Prospective studies of interventions aimed at improving care in this setting may provide insight 
on how to improve care, ${ }^{32,33}$ although challenges would remain regarding widespread implementation.

\section{Opportunities for Improvement}

Unfortunately, there have been few evidence-based improvements in medical therapy for acute HF over the past 40 years. $^{34-36}$ Amid growing pressure to improve postdischarge outcomes and reduce financial burdens associated with acute HF care, incentives for innovation are increasingly favorable. Moving treatments for acute HF outside of the hospital is an opportunity to improve the value of health care by reducing health care resource utilization, improving patient quality of life, and improving postdischarge readmission rates. Following are considerations for designing out-of-the hospital treatment strategies for acute HF (Table 1).

\section{Include the Patient Perspective in Study Designs}

Study designs to evaluate treatments provided outside of the hospital should include a patient perspective. An earlier review suggests that this was largely neglected during early evaluations of $\mathrm{HF}$ remote monitoring. ${ }^{37}$ The majority of treatments for acute HF are aimed at decongestion, ${ }^{38}$ and typical end points include changes in hemodynamic status, biomarkers, symptoms, hospital stay, end-organ function, and mortality without input from patients or other stakeholders. ${ }^{39}$ The evaluation of novel treatment strategies should include patient-reported outcomes. For example, the Patient-Centered Research Into Outcomes Stroke Patients Prefer and Effectiveness Research (PROSPER) study, which is a Patient-Centered Outcomes Research Institute (PCORI) initiative examining stroke outcomes uses a primary outcome of "home time" (ie, days alive and well outside any health care institution, including hospitals and skilled nursing facilities) based on input from stroke survivor focus groups and stakeholders. ${ }^{40}$

\section{Consider the Environment}

Risk models for acute HF treatment failure, such as inhospital mortality or readmission, typically incorporate patient demographics, comorbid conditions, left ventricular ejection fraction, and readily available laboratory data. When designing new treatment strategies for patients with acute HF with the aim of improving the value of health care, one must also consider other aspects of the HF syndrome, including education and literacy level, social support, financial considerations, and the post-discharge environment. ${ }^{41}$

The importance of the post-discharge environment was highlighted in recent studies evaluating the association between community-level socioeconomic status (as opposed to individual socioeconomic factors) and readmissions for patients with HF. ${ }^{42-44}$ In one study, patients living in neighborhoods with low socioeconomic status were more likely to be readmitted for $\mathrm{HF}$ within 6 months after discharge (odds ratio 1.35 , 95\% CI 1.01-1.82) compared with patients living in neighborhoods with high socioeconomic status, and the results were consistent after multivariable adjustments for individual demographics, clinical factors, and individual socioeconomic status. ${ }^{43}$ However, a similar study using data from GWTG-HF linked to Medicare claims and more aggregate county-level data on socioeconomic status found more modest associations between county-level socioeconomic status and 30-day outcomes. ${ }^{44}$ Taken together, these 2 studies suggest that the local environment probably plays a role in readmissions, but a more detailed understanding of the community may be important.

\section{Incorporate Novel Diagnostics and Mobile Technologies}

Future out-of-hospital treatment strategies for acute $\mathrm{HF}$ will likely benefit from incorporation of emerging technologies. For example, wireless implantable hemodynamic monitoring systems are now available as a treatment strategy to reduce hospital readmissions for patients with HF. $^{45}$ The incorporation of these devices into routine practice has not been evaluated, but this technology and other types of wearable devices that routinely capture biometric

Table 1. Considerations When Designing Out-of-Hospital Treatment Strategies for Acute Heart Failure

\begin{tabular}{|c|c|}
\hline Suggestion & Description \\
\hline Incorporate the patient perspective. & $\begin{array}{l}\text { Evaluations comparing treatment strategies for acute HF must consider patient-centered } \\
\text { outcomes and not only focus on resource utilization and readmissions. }\end{array}$ \\
\hline $\begin{array}{l}\text { Consider environmental factors that influence heart } \\
\text { failure symptoms and treatments. }\end{array}$ & $\begin{array}{l}\text { Treatment strategies designed for out-of-the-hospital settings should consider appropriate } \\
\text { education levels, socioeconomic barriers, caregivers, and other aspects of the post- } \\
\text { discharge environment. }\end{array}$ \\
\hline Harness technology. & $\begin{array}{l}\text { To add value to the health care system, new treatment strategies must be efficient and } \\
\text { implemented across multiple health care settings, ideally incorporating technology } \\
\text { solutions that are scalable and offer opportunities to collect patient data across multiple } \\
\text { domains. }\end{array}$ \\
\hline Align incentives. & $\begin{array}{l}\text { Providers, payers, and policy makers must continue to align financial incentives to improve } \\
\text { care across the patient experience. The current fee-for-value system that is incorporated } \\
\text { into the fee-for-service system offers opportunity for this. }\end{array}$ \\
\hline $\begin{array}{l}\text { Consider the impact of noncardiac conditions and } \\
\text { create a multidisciplinary team. }\end{array}$ & $\begin{array}{l}\text { Noncardiac conditions greatly affect outcomes for acute HF, and strategies should consider } \\
\text { incorporating elements of disease management for comorbid conditions. Input from non- } \\
\text { HF providers will be essential. }\end{array}$ \\
\hline
\end{tabular}


data may be useful adjuncts to identify early HF symptoms in patients with either chronic HF or a recent acute HF exacerbation. For example, a treatment strategy of discharging low- to intermediate-risk patients from the ED to home instead of hospitalization may be safer if patients are also monitored with wearable activity monitors.

\section{Continue to Align Incentives}

Despite the policy changes discussed above, the current health care model continues to largely entail episodebased payments for individual events. The resulting silos of care hamper care coordination. Ongoing policy changes are likely to further challenge this paradigm and create opportunity for health care organizations to improve the longitudinal patient experience across treatment locations. For example, Medicare now provides reimbursement for transitional care management and recently announced goals to have $85 \%$ of all Medicare fee-for-service payments tied to quality or value by $2016,90 \%$ by $2018 .{ }^{46}$ Accountable care organization works to further integrate care by sharing cost savings with providers and health systems. The value and effect of such changes on reimbursement will require additional study, but they have already significantly altered the care delivery landscape for patients with acute HF.

\section{Use Every Available Tool}

The evaluation and management of acute HF is often complicated by noncardiac comorbid conditions, such as pulmonary disease, renal disease, iron deficiency, and sleep-disordered breathing. ${ }^{47,48}$ In addition, among reasons for 30-day readmission after an HF hospitalization, most are not $\mathrm{HF}$ related, including 39\%-47\% for noncardiac reasons. $^{49,50}$ Out-of-hospital treatment strategies may be improved by incorporating elements of disease management for comorbid conditions. This is particularly relevant for $\mathrm{HF}$ with preserved ejection fraction, which is increasing rapidly in prevalence and accounts for a growing share of HF hospitalizations. ${ }^{51}$ Currently, evidence-based therapies for HF with preserved ejection fraction are lacking, and guidelines emphasize the management of comorbid conditions. ${ }^{36}$

These data also suggest that effective interventions require contributions from non-HF providers. Successfully treating patients with acute HF outside the hospital will require tremendous care coordination with primary care providers, providers in other medical specialties, pharmacists, case managers, and other health care workers.

\section{Conclusion}

Current financial pressures, coupled with an urgent need to improve post-discharge outcomes, have pushed treatment of acute HF outside of the traditional hospital setting. Despite relatively limited evidence to support HF treatment outside the hospital, components of outpatient and transitional acute HF care are expanding. These emerging models offer important research opportunities to assess ambulatory approaches to acute HF care so that our rapidly evolving delivery systems optimize care efficiency and health outcomes for the millions of patients with HF.

\section{Disclosures}

Dr DeVore reports receiving research supports from the American Heart Association, Amgen, Novartis, and Thoratec; and serving as a consultant for Maquet. Dr Allen reports receiving research grants from the National Institutes of Health and the American Heart Association; and serving as a consultant for Amgen, Johnson and Johnson, and Novartis. Dr Eapen reports serving as a consultant for Amgen and as an advisory board member for Novartis, Amgen, and Cytokinetics.

\section{References}

1. Bueno H, Ross JS, Wang Y, Chen J, Vidan MT, Normand SL, et al. Trends in length of stay and short-term outcomes among Medicare patients hospitalized for heart failure, 1993-2006. JAMA 2010 303:2141-7.

2. Centers for Medicare and Medicaid Services, Department of Health and Human Services. Acute Care Hospital Inpatient Prospective Payment System: payment system fact sheet series. Available at: http://www.cms.gov/ Outreach-and-Education/Medicare-Learning-Network-MLN/MLN Products/downloads/AcutePaymtSysfctsht.pdf. Accessed April 20, 2015.

3. Baker DW, Einstadter D, Husak SS, Cebul RD. Trends in postdischarge mortality and readmissions: has length of stay declined too far? Arch Intern Med 2004;164:538-44.

4. Eapen ZJ, Reed SD, Li Y, Kociol RD, Armstrong PW, Starling RC, et al. Do countries or hospitals with longer hospital stays for acute heart failure have lower readmission rates? Findings from ASCEND-HF. Circ Heart Fail 2013;6:727-32.

5. Jencks SF, Williams MV, Coleman EA. Rehospitalizations among Patients in the Medicare Fee-for-Service Program. N Engl J Med 2009;360:1418-28.

6. Vidic A, Chibnall JT, Hauptman PJ. Heart failure is a major contributor to hospital readmission penalties. J Card Fail 2015;21:134-7.

7. Hospital to Home $(\mathrm{H} 2 \mathrm{H})$ Initiative. Available at: http://cvquality. acc.org/Initiatives/H2H.aspx. Accessed April 20, 2015.

8. TARGET: HF. Available at: http://www.heart.org/HEARTORG/Health careResearch/TargetHFStroke/TargetHF/Target-HF_UCM_307433 SubHomePage.jsp. Accessed April 20, 2015.

9. Collins S, Storrow AB, Albert NM, Butler J, Ezekowitz J, Felker GM, et al. Early management of patients with acute heart failure: state of the art and future directions. A consensus document from the Society for Academic Emergency Medicine/Heart Failure Society of America Acute Heart Failure Working Group. J Card Fail 2015;21:27-43.

10. Pang PS, Jesse R, Collins SP, Maisel A. Patients with acute heart failure in the emergency department: do they all need to be admitted? J Card Fail 2012;18:900-3.

11. Binanay C, Califf RM, Hasselblad V, O'Connor CM, Shah MR, Sopko G, et al. Evaluation study of congestive heart failure and pulmonary artery catheterization effectiveness: the ESCAPE trial. JAMA 2005;294:1625-33.

12. Konstam MA, Gheorghiade M, Burnett JC Jr, Grinfeld L, Maggioni AP, Swedberg K, et al. Effects of oral tolvaptan in patients hospitalized for worsening heart failure: the EVEREST outcome trial. JAMA 2007;297:1319-31.

13. Massie BM, O’Connor CM, Metra M, Ponikowski P, Teerlink JR, Cotter G, et al. Rolofylline, an adenosine A1-receptor antagonist, in acute heart failure. N Eng1 J Med 2010;363:1419-28. 
14. O'Connor CM, Starling RC, Hernandez AF, Armstrong PW, Dickstein K, Hasselblad V, et al. Effect of nesiritide in patients with acute decompensated heart failure. N Engl J Med 2011;365: 32-43.

15. Schuur JD, Venkatesh AK. The growing role of emergency departments in hospital admissions. N Engl J Med 2012;367:391-3.

16. Storrow AB, Jenkins CA, Self WH, Alexander PT, Barrett TW, Han JH, et al. The burden of acute heart failure on U.S. emergency departments. JACC Heart Fail 2014;2:269-77.

17. Auble TE, Hsieh M, Gardner W, Cooper GF, Stone RA, McCausland JB, et al. A prediction rule to identify low-risk patients with heart failure. Acad Emerg Med 2005;12:514-21.

18. Collins SP, Pang PS, Fonarow GC, Yancy CW, Bonow RO, Gheorghiade M. Is hospital admission for heart failure really necessary? The role of the emergency department and observation unit in preventing hospitalization and rehospitalization. J Am Coll Cardiol 2013;61:121-6.

19. Mason D. The unintended consequences of the "observation status" policy. JAMA 2014;312:1959-60.

20. Centers for Medicare and Medicaid Services. Medicare Hospital Quality Chartbook. Performance report on outcome measures. Available at: http://www.cms.gov/Medicare/Quality-Initiatives-PatientAssessment-Instruments/HospitalQualityInits/Downloads/MedicareHospital-Quality-Chartbook-2014.pdf. February 11, 2015.

21. Wiler JL, Ross MA, Ginde AA. National study of emergency department observation services. Acad Emerg Med 2011;18:959-65.

22. Schrager J, Wheatley M, Georgiopoulou V, Osborne A, Kalogeropoulos A, Hung O, et al. Favorable bed utilization and readmission rates for emergency department observation unit heart failure patients. Acad Emerg Med 2013;20:554-61.

23. Storrow AB, Collins SP, Lyons MS, Wagoner LE, Gibler WB, Lindsell CJ. Emergency department observation of heart failure: preliminary analysis of safety and cost. Congest Heart Fail 2005;11:68-72.

24. Hasegawa K, Tsugawa Y, Camargo CA, Brown DF. Frequent utilization of the emergency department for acute heart failure syndrome: a population-based study. Circ Cardiovasc Qual Outcomes 2014;7: 735-42.

25. Desai AS, Stevenson LW. Rehospitalization for heart failure: predict or prevent? Circulation 2012;126:501-6.

26. Hernandez AF, Greiner MA, Fonarow GC, Hammill BG, Heidenreich PA, Yancy CW, et al. Relationship between early physician follow-up and 30-day readmission among Medicare beneficiaries hospitalized for heart failure. JAMA 2010;303:1716-22.

27. Albert NM, Barnason S, Deswal A, Hernandez A, Kociol R, Lee E, et al. Transitions of care in heart failure: a scientific statement from the American Heart Association. Circ Heart Fail 2015;8:384-409.

28. Feltner C, Jones CD, Cené CW, Zheng Z-J, Sueta CA, CokerSchwimmer EJ, et al. Transitional care interventions to prevent readmissions for persons with heart failure: a systematic review and meta-analysis. Ann Intern Med 2014;160:774-84.

29. Allen LA, Hernandez AF, Peterson ED, Curtis LH, Dai D, Masoudi FA, et al. Discharge to a skilled nursing facility and subsequent clinical outcomes among older patients hospitalized for heart failure. Circ Heart Fail 2011;4:293-300.

30. Jurgens CY, Goodlin S, Dolansky M, Ahmed A, Fonarow GC, Boxer R, et al. Heart failure management in skilled nursing facilities. J Card Fail 2015;21:263-99. http://www.ncbi.nlm.nih.gov/pubm $\mathrm{ed} / 25863664$.

31. Boxer RS, Dolansky MA, Frantz MA, Prosser R, Hitch JA, Pina IL. The Bridge Project: improving heart failure care in skilled nursing facilities. J Am Med Directors Assoc 2012;13:83.e1-e7.

32. Dolansky MA, Hitch JA, Pina IL, Boxer RS. Improving heart failure disease management in skilled nursing facilities: lessons learned. Clin Nurs Res 2013;22:432-47.

33. Boxer RS, Dolansky MA, Bodnar CA, Singer ME, Albert JM, Gravenstein S. A randomized trial of heart failure disease management in skilled nursing facilities: design and rationale. J Am Med Directors Assoc 2013;14:710.e5-e11.
34. Ramirez A, Abelmann WH. Cardiac decompensation. N Engl J Med 1974;290:499-501.

35. McMurray JJV, Adamopoulos S, Anker SD, Auricchio A, Böhm M, Dickstein K, et al. ESC guidelines for the diagnosis and treatment of acute and chronic heart failure 2012: the Task Force for the Diagnosis and Treatment of Acute and Chronic Heart Failure 2012 of the European Society of Cardiology. Developed in collaboration with the Heart Failure Association (HFA) of the ESC. Eur Heart J 2012;33:1787-847.

36. Yancy CW, Jessup M, Bozkurt B, Butler J, Casey DE, Drazner MH, et al. 2013 ACCF/AHA guideline for the management of heart failure: a report of the American College of Cardiology Foundation/American Heart Association Task Force on Practice Guidelines. Circulation 2013;128:e240-327.

37. Kraai IH, Luttik ML, de Jong RM, Jaarsma T, Hillege HL. Heart failure patients monitored with telemedicine: patient satisfaction, a review of the literature. J Card Fail 2011;17:684-90.

38. Ambrosy AP, Fonarow GC, Butler J, Chioncel O, Greene SJ, Vaduganathan M, et al. The global health and economic burden of hospitalizations for heart failure: lessons learned from hospitalized heart failure registries. J Am Coll Cardiol 2014;63:1123-33.

39. Allen LA, Hernandez AF, O'Connor CM, Felker GM. End points for clinical trials in acute heart failure syndromes. J Am Coll Cardiol 2009;53:2248-58.

40. Patient-Centered Research Into Outcomes Stroke Patients Prefer and Effectiveness Research (PROSPER) Project Summary. Available at: http://www.pcori.org/research-results/2013/patientcentered-research-outcomes-stroke-patients-prefer-and-effectiveness. Accessed April 21, 2015.

41. Hersh AM, Masoudi FA, Allen LA. Postdischarge environment following heart failure hospitalization: expanding the view of hospital readmission. J Am Heart Assoc 2013;2:e000116.

42. Kind AJH, Jencks S, Brock J, Yu M, Bartels C, Ehlenbach W, et al. Neighborhood socioeconomic disadvantage and 30-day rehospitalization: a retrospective cohort study. Ann Intern Med 2014;161: 765-74.

43. Bikdeli B, Wayda B, Bao H, Ross JS, Xu X, Chaudhry SI, et al. Place of residence and outcomes of patients with heart failure: analysis from the telemonitoring to improve heart failure outcomes trial. Circ Cardiovasc Qual Outcomes 2014;7:749-56.

44. Eapen ZJ, McCoy LA, Fonarow GC, Yancy CW, Miranda ML, Peterson ED, et al. Utility of socioeconomic status in predicting 30-day outcomes after heart failure hospitalization. Circ Heart Fail $2015 ; 8: 473-80$.

45. Abraham WT, Adamson PB, Bourge RC, Aaron MF, Costanzo MR, Stevenson LW, et al. Wireless pulmonary artery haemodynamic monitoring in chronic heart failure: a randomised controlled trial. Lancet 2011;377:658-66.

46. Burwell SM. Setting value-based payment goals-HHS efforts to improve U.S. health care. N Engl J Med 2015;372:897-9.

47. Mentz RJ, Felker GM. Noncardiac comorbidities and acute heart failure patients. Heart Failure Clin 2013;9:359-67. vii.

48. Mentz RJ, Kelly JP, von Lueder TG, Voors AA, Lam CS, Cowie MR, et al. Noncardiac comorbidities in heart failure with reduced versus preserved ejection fraction. J Am Coll Cardiol 2014;64:2281-93.

49. O'Connor CM, Miller AB, Blair JE, Konstam MA, Wedge P, Bahit MC, et al. Causes of death and rehospitalization in patients hospitalized with worsening heart failure and reduced left ventricular ejection fraction: results from Efficacy of Vasopressin Antagonism in Heart Failure Outcome Study With Tolvaptan (EVEREST) program. Am Heart J 2010;159:841-849.e1.

50. Dharmarajan K, Hsieh AF, Lin Z, Bueno H, Ross JS, Horwitz LI, et al. Diagnoses and timing of 30-day readmissions after hospitalization for heart failure, acute myocardial infarction, or pneumonia. JAMA 2013;309:355-63.

51. Steinberg BA, Zhao X, Heidenreich PA, Peterson ED, Bhatt DL, Cannon CP, et al. Trends in patients hospitalized with heart failure and preserved left ventricular ejection fraction: prevalence, therapies, and outcomes. Circulation 2012;126:65-75. 